\title{
Fluid as a critical biomarker in neovascular age-related macular degeneration management: literature review and consensus recommendations
}

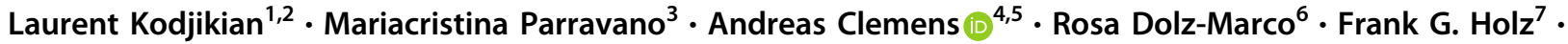 \\ Marion R. Munk ${ }^{8} \cdot$ Massimo Nicolò $^{9} \cdot$ Federico Ricci ${ }^{10} \cdot$ Rufino Silva $\mathbb{1}^{11,12,13} \cdot$ S. James Talks ${ }^{14}$. \\ Rohini Kumar Verma ${ }^{4} \cdot$ Javier Zarranz-Ventura $\mathbb{C}^{15,16} \cdot$ Sandrine A. Zweifel $\mathbb{C}^{17,18}$
}

Received: 6 October 2020 / Revised: 11 February 2021 / Accepted: 22 February 2021 / Published online: 1 April 2021

(c) The Author(s) 2021. This article is published with open access

\begin{abstract}
Current guidelines on the management of patients with neovascular age-related macular degeneration (nAMD) lack clear recommendations on the interpretation of fluid as seen on optical coherence tomography (OCT) imaging and the incorporation of this information into an ongoing disease treatment strategy. Our objective was to review current guidelines and scientific evidence on the role of fluid as a biomarker in the management of nAMD, and develop a clinically oriented, practical algorithm for diagnosis and management based on a consensus of expert European retinal specialists. PubMed was searched for articles published since 2006 relating to the role of fluid in nAMD. A total of 654 publications were screened for relevance and 66 publications were included for review. Of these, 14 were treatment guidelines, consensus statements and systematic reviews or meta-analyses, in which OCT was consistently recommended as an important tool in the initial diagnosis and ongoing management of nAMD. However, few guidelines distinguished between types of fluid when providing recommendations. A total of 52 publications reported primary evidence from clinical trials, studies, and chart reviews. Observations from these were sometimes inconsistent, but trends were observed with regard to features reported as being predictive of visual outcomes. Based on these findings, diagnostic recommendations and a treatment algorithm based on a treat-and-extend (T\&E) regimen were developed. These provide guidance on the diagnosis of nAMD as well as a simple treatment pathway based on the T\&E regimen, with treatment decisions made according to the observations of fluid as a critical biomarker for disease activity.
\end{abstract}

Sandrine A. Zweifel

Sandrine.Zweifel@usz.ch

1 Department of Ophthalmology, Croix-Rousse University Hospital, Hospices Civils de Lyon, Lyon, France

2 UMR-CNRS 5510 Matéis, Villeurbanne, INSA de Lyon, Université Claude Bernard Lyon 1, University of Lyon, Lyon, France

3 IRCCS - Fondazione Bietti, Rome, Italy

4 Novartis Pharma AG, Basel, Switzerland

5 Department of Cardiology and Angiology I, Heart Center Freiburg University, Faculty of Medicine, University of Freiburg, Freiburg im Breisgau, Germany

6 Macula Unit, Oftalvist Clinic, Valencia, Spain

7 Department of Ophthalmology, University of Bonn, Bonn, Germany

8 Department of Ophthalmology, Inselspital, University Hospital Bern, Bern, Switzerland

9 University Eye Clinic of Genoa DINOGMI, Ospedale Policlinico San Martino - IRCCS, Genoa, Italy
10 Department of Experimental Medicine, University Tor Vergata, Rome, Italy

11 Coimbra Institute for Clinical and Biomedical Research, Faculty of Medicine, University of Coimbra (ICBR-FMUC), Coimbra, Portugal

12 Department of Ophthalmology, Centro Hospitalar e Universitário de Coimbra (CHUC), Coimbra, Portugal

13 Association of Innovation and Biomedical Research in Light and Image (AIBILI), Coimbra, Portugal

14 Newcastle upon Tyne Hospitals NHS Foundation Trust, Newcastle upon Tyne, UK

15 Hospital Clínic de Barcelona, Barcelona, Spain

16 Institut de Investigacions Biomediques August Pi i Sunyer (IDIBAPS), Barcelona, Spain

17 Department of Ophthalmology, University Hospital Zurich, Zurich, Switzerland

18 University of Zurich, Zurich, Switzerland 


\section{Introduction}

Since the widespread introduction of optical coherence tomography (OCT) for the visualisation of the back of the eye in patients with eye diseases such as neovascular agerelated macular degeneration (nAMD), the evaluation of lesion morphology using OCT has become a key part of the clinical decision-making pathway [1]. Markers for disease activity based on OCT, including intraretinal and subretinal as well as subretinal pigment epithelium (RPE) fluid, are crucial for guiding management and treatment frequency of nAMD patients.

Recent advances in OCT technology have led to increases in speed and resolution that permit the detection of small structural changes to the retinal layers [2]. However, the interpretation of OCT images can be complex and challenging. Although this is an area of considerable scientific interest and extensive literature exists which attempts to evaluate the influence of different types of fluid on outcomes in nAMD, current guidelines may be lacking or open to misinterpretation when it comes to translating the diagnostic findings from an OCT into an ongoing disease treatment strategy. Clear treatment recommendations that consider both clinical and real-world considerations are therefore required.

The objective of this consensus article is to review the current guidelines and scientific evidence on the role of fluid as a biomarker in the management of nAMD and provide clinically useful recommendations based on a consensus of expert European retinal specialists. Furthermore, limitations of current literature and areas of further research are also highlighted.

\section{Methods}

A preliminary review of the literature on the role of fluid in the management of nAMD was performed by Novartis in preparation for a roundtable discussion with European retinal specialists (consensus panel, consisting of LK, MP, RDM, FGH, MRM, MN, FR, RS, SJT, JZV and SAZ), held in Zurich, Switzerland (19 July 2019). During this initial meeting, the available scientific evidenceand the lack of it-were discussed, resulting in the proposal from the consensus panel to develop simplified treatment recommendations in nAMD. The literature review was subsequently repeated with revised search parameters and the updated results were subject to further review by the consensus panel during the development of the treatment recommendations, ensuring scientific rigour and unbiased interpretation. Novartis was not involved in the interpretation of the literature search
Table 1 Search parameters.

Parameters

(“age-related macular degeneration"[All Fields] OR AMD[All

Fields]) AND fluid[All Fields]

AND date limits: 2006-2019

AND one or more of the secondary search terms:

- Visual acuity

- Visual function

- Vision

- Association or correlation or predictor or biomarker and visual acuity or visual function $o r$ vision

- Association or correlation or predictor or biomarker and disease progression

- Fluctuations or fluctuating or variability and CST or CRT or thickness

- Pathophysiology

- Diagnosis

- Management

- Anatomical

- Structural

- Prognosis

$\overline{A M D}$ age-related macular degeneration, $C R T$ central retinal thickness, CST central subfield thickness.

results or the development of the treatment recommendations.

The repeated literature search of PubMed was performed according to the predefined search parameters shown in Table 1, with other relevant publications included from information sources such as recent congress presentations and educational resources. The resulting publications were screened by title and abstract for relevance and according to the following exclusion criteria: case reports and studies with fewer than 50 patients; opinion pieces other than expert consensus recommendations and guidelines; nonEnglish language publications; and publication date prior to 2006. The scientific evidence that was retrieved by the search was tabulated and graded according to recent European guidance [3].

The evidence was discussed by the consensus panel and used, along with their expert opinion and experience, to inform the development of a consensus management algorithm for patients with nAMD based primarily on observations of fluid from OCT monitoring. The nAMD-specific terminology used within this article follows recent consensus nomenclature for reporting nAMD data [4]. The term intraretinal fluid (IRF) is used throughout the document to standardise the different terms used to describe the presence of fluid within the retina including intraretinal cystoid oedema, intraretinal cysts, cystoid oedema, cystoid macular oedema and retinal fluid. 


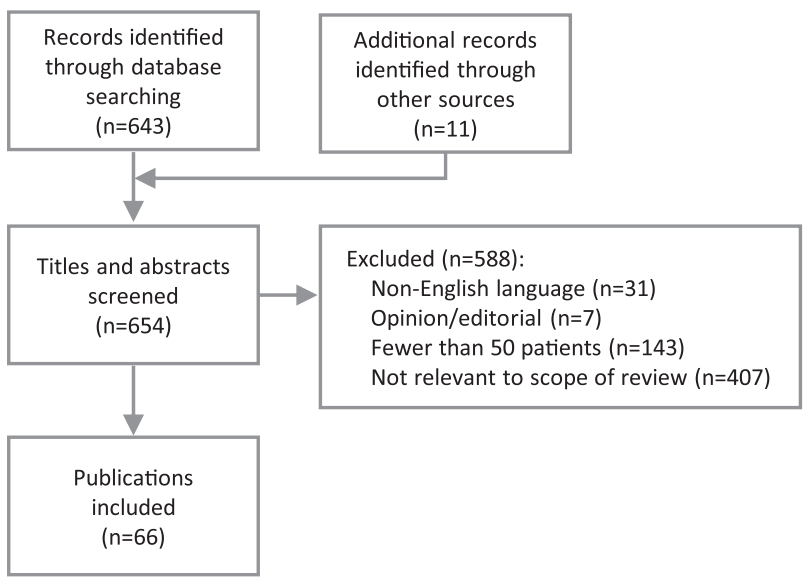

Fig. 1 Literature review flow diagram. Sixty-six eligible publications were selected for inclusion.

\section{Results}

The literature review was performed on September 25, 2019 (Fig. 1). After screening of 654 publications and excluding those that were not relevant or were outside the scope of the review, a total of 66 publications were included. Of these, 14 publications were treatment guidelines, consensus statements and systematic reviews or meta-analyses, while 52 publications reported primary evidence from clinical trials, studies, and chart reviews.

\section{Treatment guidelines}

Six treatment guidelines from institutions in Europe and the USA were retrieved by the search. In the Royal College of Ophthalmologists' (RCOphth) guidance on the use of ranibizumab in nAMD from 2009, new subretinal fluid (SRF) with or without haemorrhage is included as one criteria for treatment initiation, while their definition of disease activity for continuation of treatment includes IRF, SRF, sub-RPE fluid and haemorrhage [5]. In later guidelines on AMD from 2013, the RCOphth provided similar recommendations relating to fluid [6]. These latter guidelines have since been archived following the publication of the National Institute for Health and Care Excellence (NICE) guidelines on age-related macular degeneration (AMD) in January 2018. In these, NICE states that OCT should be offered to individuals with suspected active nAMD, or for ongoing monitoring of patients with active nAMD. No specific guidance is given with regard to fluid and treatment or management of the condition [7].

Few guidelines distinguished between types of fluid when providing recommendations, with the same retreatment approach generally recommended regardless of the type and location of fluid observed. One of the few that made a distinction between fluid types was the 2014
EURETINA guideline on nAMD, which advised that IRF, SRF and RPE detachments are important signs of neovascular activity independent of central retinal thickness (CRT), and that a 'zero tolerance' approach to OCT criteria is justified given the rapid progression of exudative features and progressive loss of vision when initiation of treatment is delayed in nAMD. However, longstanding persistent IRF should be considered a sign of irreversible retinal damage which should not prompt continued retreatment. Performing OCT was recommended as the most useful tool for evaluating morphological changes since it provides the most accurate reflection of the recurrence of disease activity. Qualitative morphology-based OCT data were considered to be more sensitive than current quantitative measurements such as CRT for detecting choroidal neovascularisation (now termed macular neovascularisation [MNV]) activity [8].

In the American Academy of Ophthalmology preferred practice pattern for AMD from 2015, there is no specific mention of how to interpret retinal fluid in diagnosis or follow-up, other than a statement that as-needed treatment should be based on the presence or absence of SRF or IRF [9]. Finally, recommendations on outcome measures for macular degeneration provided by the International Consortium for Health Outcomes Measurement and a group of experts in 2016 advised that the presence of IRF, SRF or haemorrhage attributable to neovascular lesion activity (as determined by the treating ophthalmologist) should be assessed at each clinic visit [10].

\section{Consensus statements}

A number of expert consensus statements have provided guidance on the management of nAMD including recommendations relating to fluid and other anatomical parameters visualised using OCT. These are broadly consistent but differ in the detail of interpreting the various morphological features.

In 2011, a group of 22 European experts provided consensus recommendations for anti-vascular endothelial growth factor (VEGF) management of nAMD based on morphological criteria. Suggested retreatment criteria under a pro-re-nata (PRN) regimen included IRF, SRF, diffuse foveal thickening and expanding serous pigment epithelium detachment (PED). Criteria for delaying treatment included the absence of the above criteria, stable serous PED and stable IRF that has not responded to three intravitreal injections [11]. Notably, at the time of these recommendations, retreatment criteria were based on the assessment of a single transfoveal OCT image [11]. A committee of UKbased retinal experts published a consensus paper defining response to anti-VEGF therapy in nAMD in 2015. They noted that there is often little correlation between 
morphological and functional responses to anti-VEGF treatments, and so recommended a combination of morphology and function as the means of determining treatment response, with the morphology component defined as IRF, SRF and retinal thickening [12].

In a 2017 expert round-table consensus on the treatment of nAMD with aflibercept in the second year of therapy, fluid was a recommended consideration when making the decision to maintain a fixed regimen or move to a treat-andextend (T\&E) dosing schedule. The criteria for not extending the treatment interval included persistent macular fluid with stable vision, recurrent fluid, and decrease in vision in the presence of fluid. Extension of intervals between treatments was recommended for eyes with no macular fluid and stable vision [13].

A recent Greek consensus statement on the management of nAMD recognised the importance of morphological signs of disease activity observed using OCT, which the authors note correspond to early signs of recurrence prior to measurable loss of VA. The main anatomic parameters to be taken into consideration according to their recommendations were CRT, SRF, IRF, anatomy of the outer retinal layers and PED [14].

\section{Systematic reviews}

Four systematic reviews were included in the literature review. The earliest of these was a systematic review on OCT for diagnosis, monitoring and guiding treatment for nAMD by Mowatt and colleagues from 2014, which concluded that strategies involving OCT alone for diagnosis and/or monitoring were unlikely to be cost-effective, while those that also included fluorescein angiography (FA) and other imaging techniques were more likely to be considered cost-effective. However, many of the studies included in this review used older, time-domain OCT technology which may have compromised the specificity of the technique in terms of detecting active nAMD. For the purposes of this review, nAMD was considered to be active or inactive, with no specific discussion relating to fluid [15]. In contrast, a review by Schmid-Erfurth and Waldstein from 2016 provided detailed information on imaging biomarkers in nAMD. The authors concluded that CRT is an inferior prognostic biomarker for guiding retreatment compared with localisation of fluid in different compartments, including IRF and SRF. IRF at baseline is negatively associated with VA, while SRF at baseline (i.e., in naive patients) is associated with superior visual benefits and a lower rate of progression towards atrophy. The finding of SRF is associated with all lesion types and is typically the first exudative sign in Type 1 lesions. RPE detachment was identified as unresponsive to therapy and responsible for visual decline [16]. A later systematic review on OCT in the management of AMD by the same group provided a detailed discussion of morphological features indicative of disease activity, but was accompanied by no clear guidance for treatment [17].

A systematic review of the evidence on using morphological predictors to modify treatment protocols in nAMD was performed by Ashraf et al. [18], finding that a good response in terms of reduction in SRF at 12 weeks predicted good visual outcomes, but that patients with PED and IRF achieved smaller visual gains and their treatment intervals should be extended with caution.

\section{Primary evidence}

The 52 primary publications of clinical trials and studies retrieved by the literature search were reviewed for relevant detail on the role or impact of fluid in nAMD. Of these, one publication was the primary output of a randomised controlled trial (RCT) [19], 21 publications were post-hoc analyses, exploratory analyses and prospective cohort studies related to several medium and large RCTs (ABC trial [20], PIER [21], CATT [22-27], MONT BLANC [28], EXCITE [29, 30], GEFAL [31], VIEW 1 and 2 [32-36] and HARBOR [37-39]), 5 publications described prospective, nonrandomised studies, and the remaining 25 publications were retrospective chart reviews and case series. Table 2 provides a summary of the studies and their findings, while Table 3 compares features of several of the key RCTs of anti-VEGF therapy in nAMD, including the retreatment criteria applied to the flexible treatment arms or phases of these trials.

Several studies reported that the presence of baseline SRF predicts a good response to anti-VEGF treatment, resulting in favourable visual outcomes [25, 26, 37, 40-42]. Evidence also suggests that small amounts (defined by the FLUID study as less than $200 \mu \mathrm{m}$ ) of residual stable SRF can be tolerated without impact on VA $[19,43]$. However, one study reported that recurrent SRF is predictive of a poor functional prognosis [44]. A substantial number of studies reported consistent findings indicating that the presence of IRF (at baseline or recurring) is predictive of a poor prognosis [22, 23, 25, 27, 31, 41, 42, 44-52]. New or growing sub-RPE fluid is reported in one study as being an early sign of conversion to nAMD [53], while another study found an increase in sub-RPE fluid to be a marker for progressive disease activity which warrants treatment [32]. While this could be considered a useful predictive biomarker if observed over time, it should be noted that the presence of sub-RPE fluid in a single OCT scan without the presence of SRF and IRF is not necessarily indicative of disease progression.

Several publications found the type or spatial localisation of fluid to have limited prognostic value in terms of predicting response to anti-VEGF therapy [33, 38, 54, 55]. In the VIEW studies, a post-hoc analysis reported that BCVA 


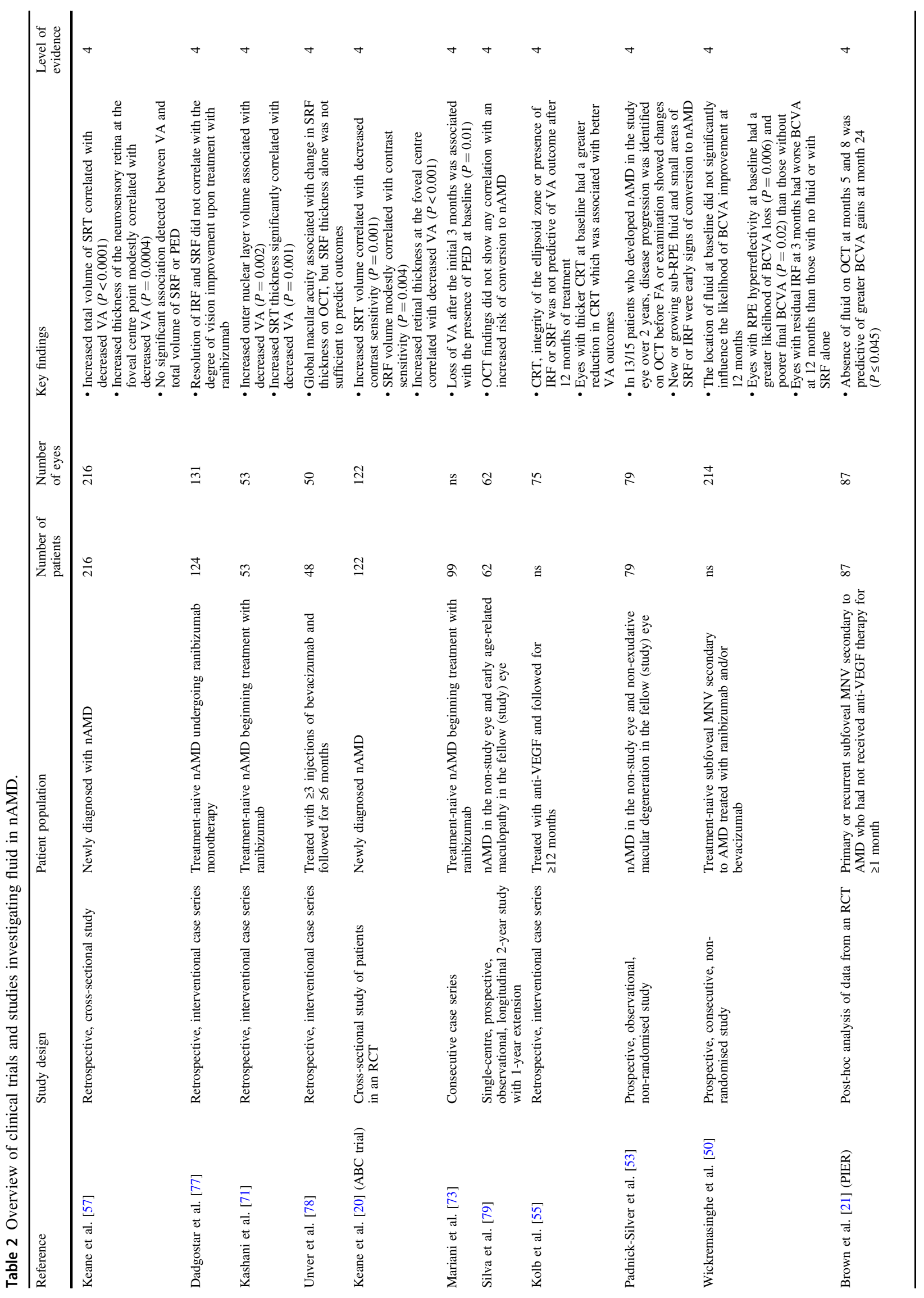




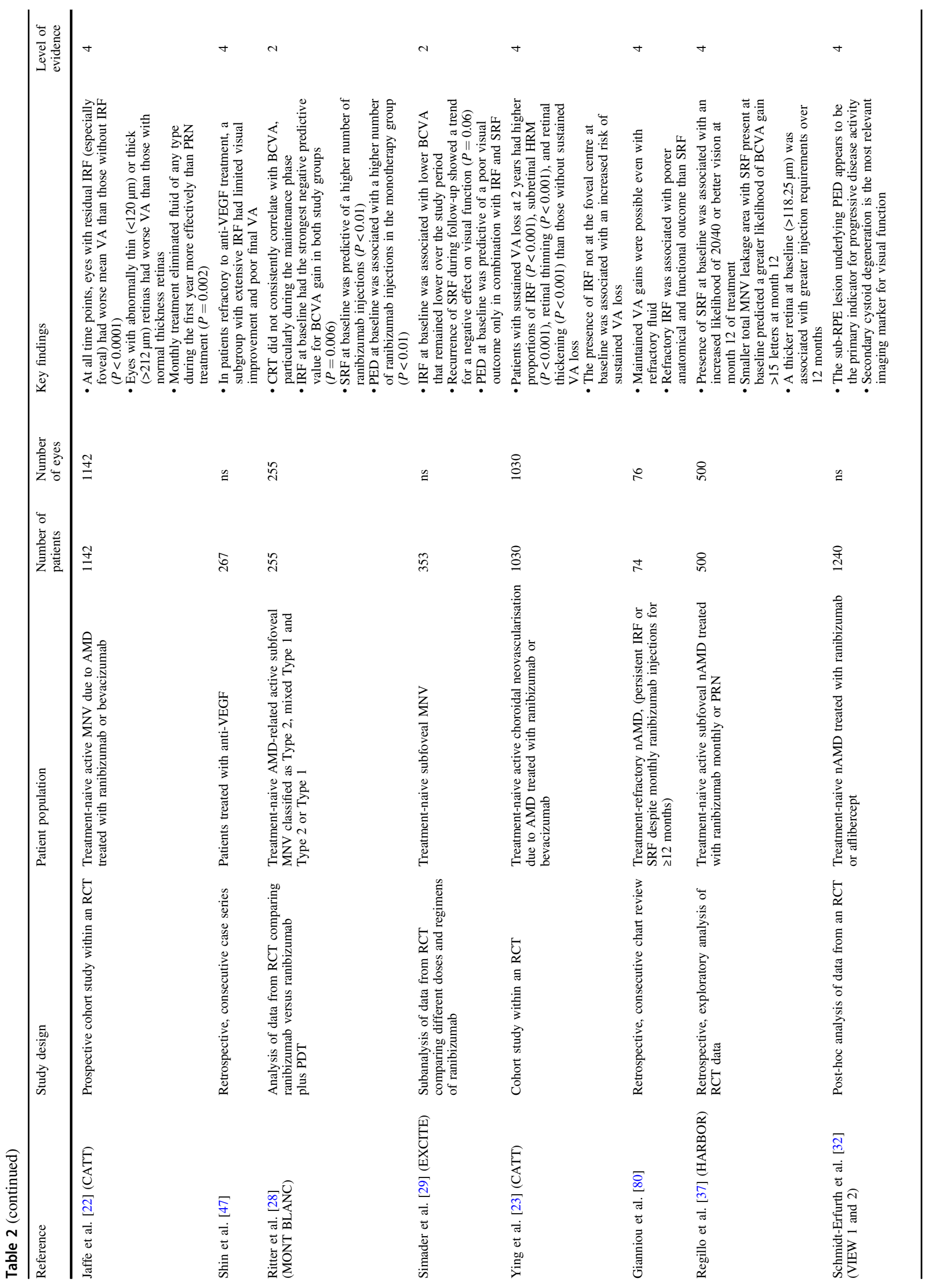




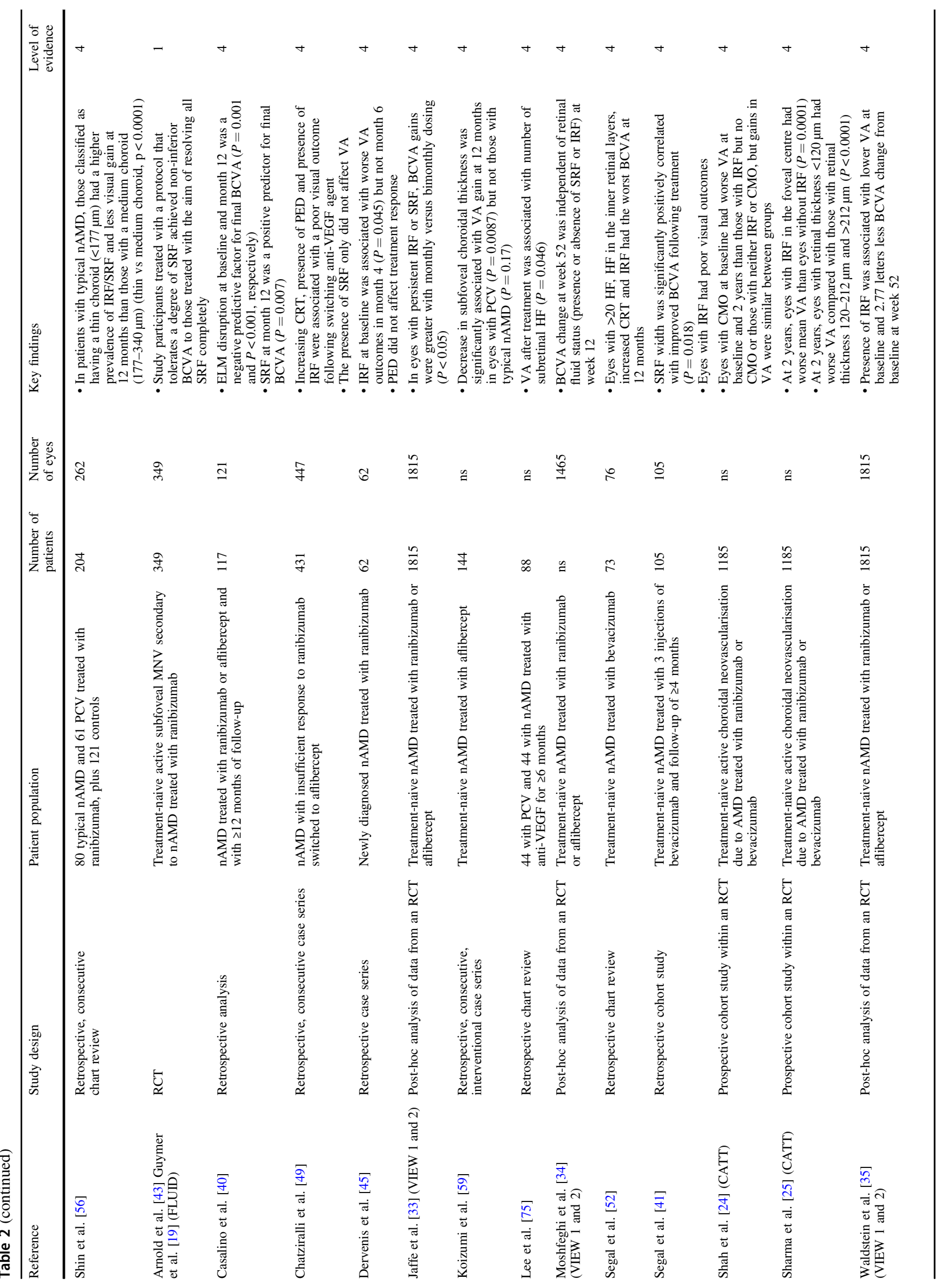




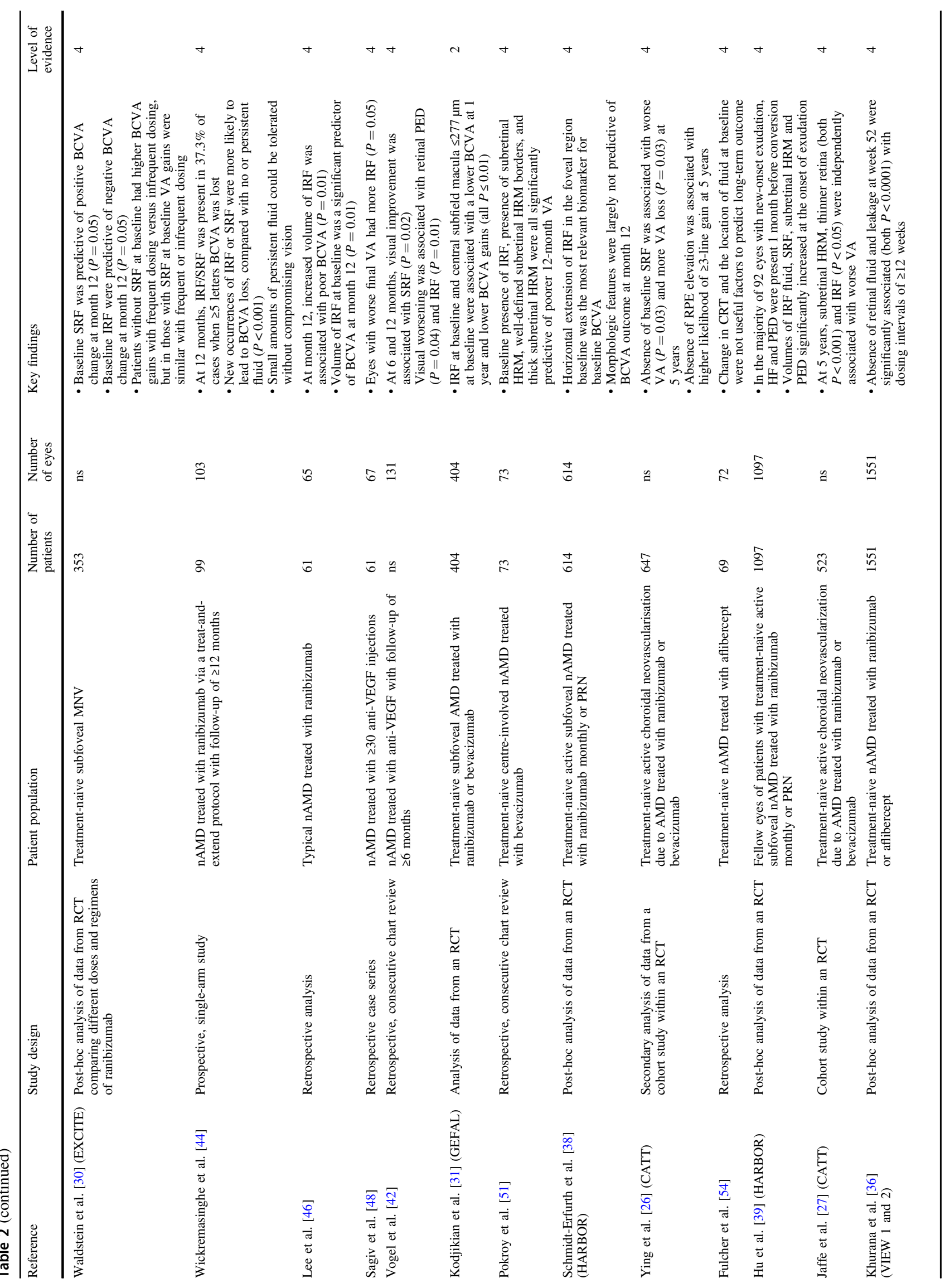




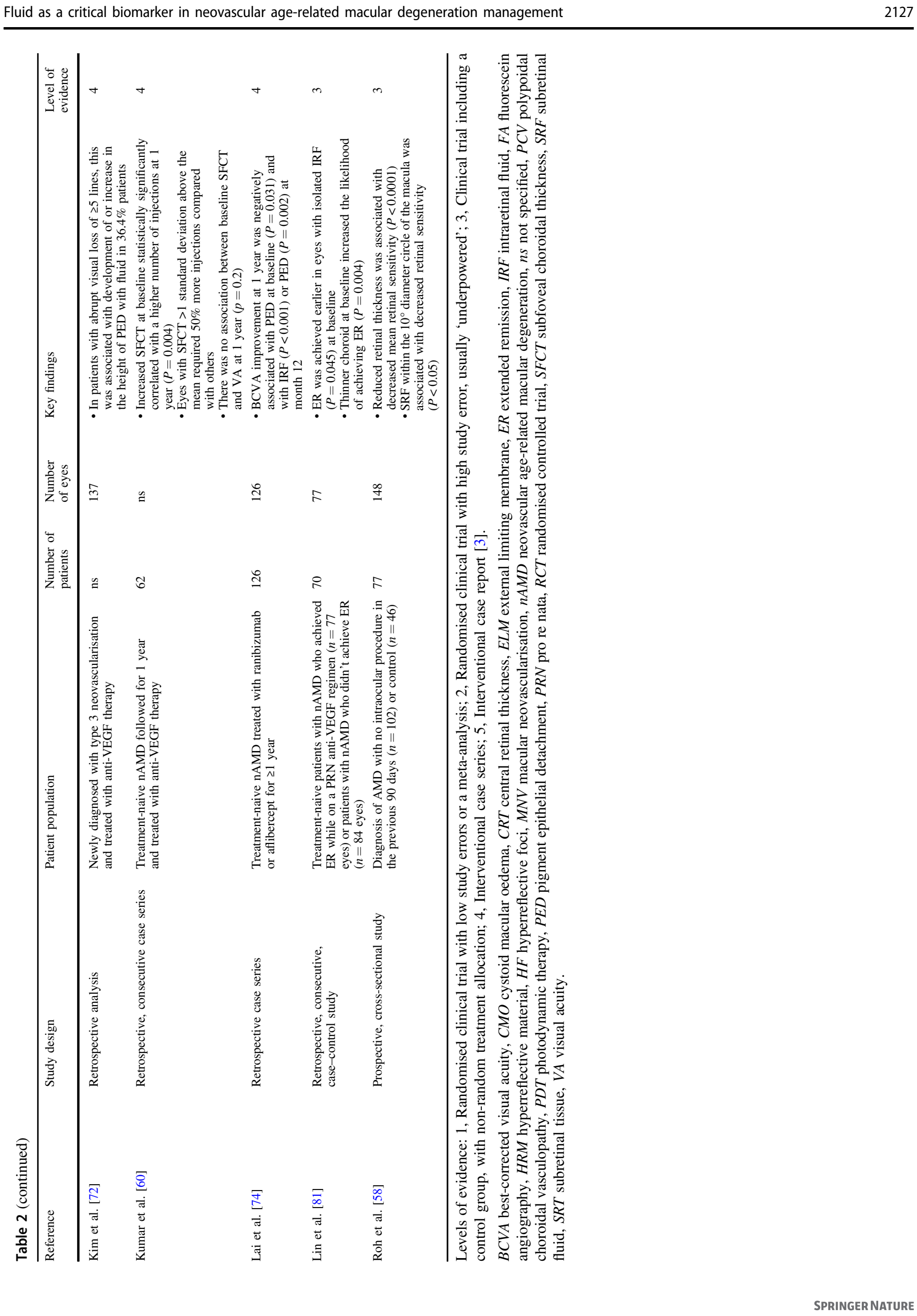




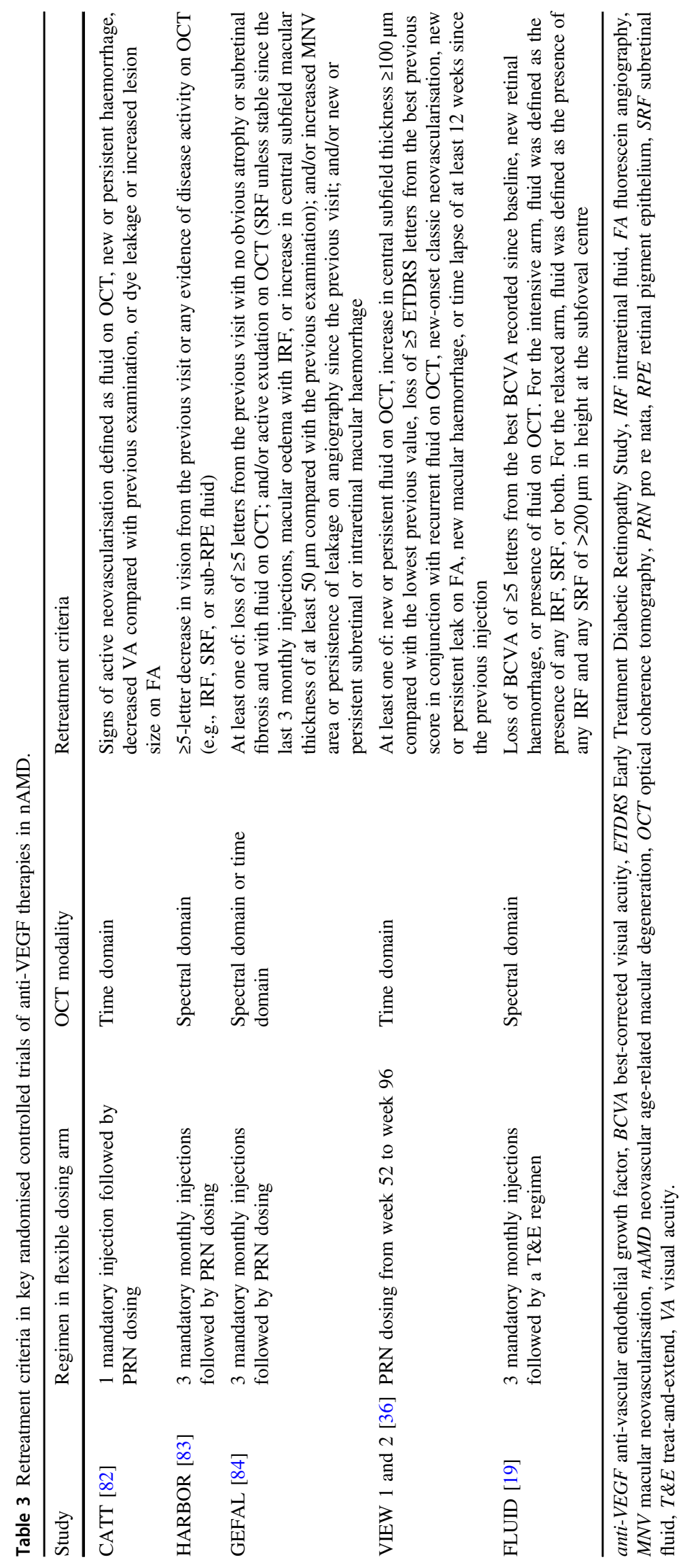


change from baseline to week 52 was independent of the presence or absence of fluid at week 12 [34]. However, contrasting evidence from the PIER study suggests that an absence of fluid on OCT is predictive of greater BCVA gains with anti-VEGF treatment [21].

A significant number of studies found either abnormally thick or abnormally thin retinas to be associated with poor outcomes [20, 22, 25, 27, 31, 49, 52, 56, 57]. Reduced retinal thickness has been associated with decreased retinal sensitivity [58], and an increased total volume of subretinal tissue has been correlated with decreased VA or contrast sensitivity [20, 57]. In a retrospective study of patients initially treated with ranibizumab and then switched to aflibercept, subfoveal thickening and increased retinal central subfield thickness were reported to be predictive of poor prognosis in non-treatment naive patients [49]. In contrast, however, two studies reported that change in retinal thickness is not predictive of treatment outcomes [54, 59].
Finally, a small number of publications commented on correlations between fluid and required anti-VEGF injection frequency. Two publications reported that a thicker retina at baseline was associated with greater injection requirements $[37,60]$, while another stated that the presence of SRF was predictive of the need for a higher injection frequency [28]. A post-hoc analysis of the VIEW studies reported that the absence of retinal fluid at 1 year was predictive of the ability to achieve extended treatment intervals of at least 12 weeks [36].

\section{Algorithm for the management of nAMD}

Based on the available scientific evidence described above and the experience of the consensus panel, an algorithm for the most optimal management of patients with nAMD based on fluid observed using OCT and other imaging technologies is recommended, irrespective of country guidance and resource constraints, as shown in Fig. 2. a

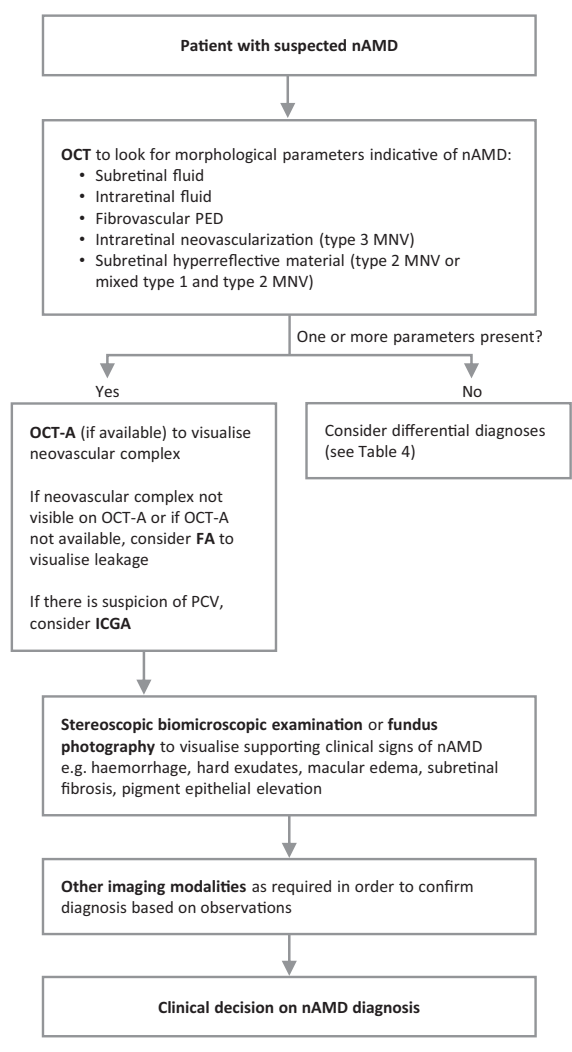

b

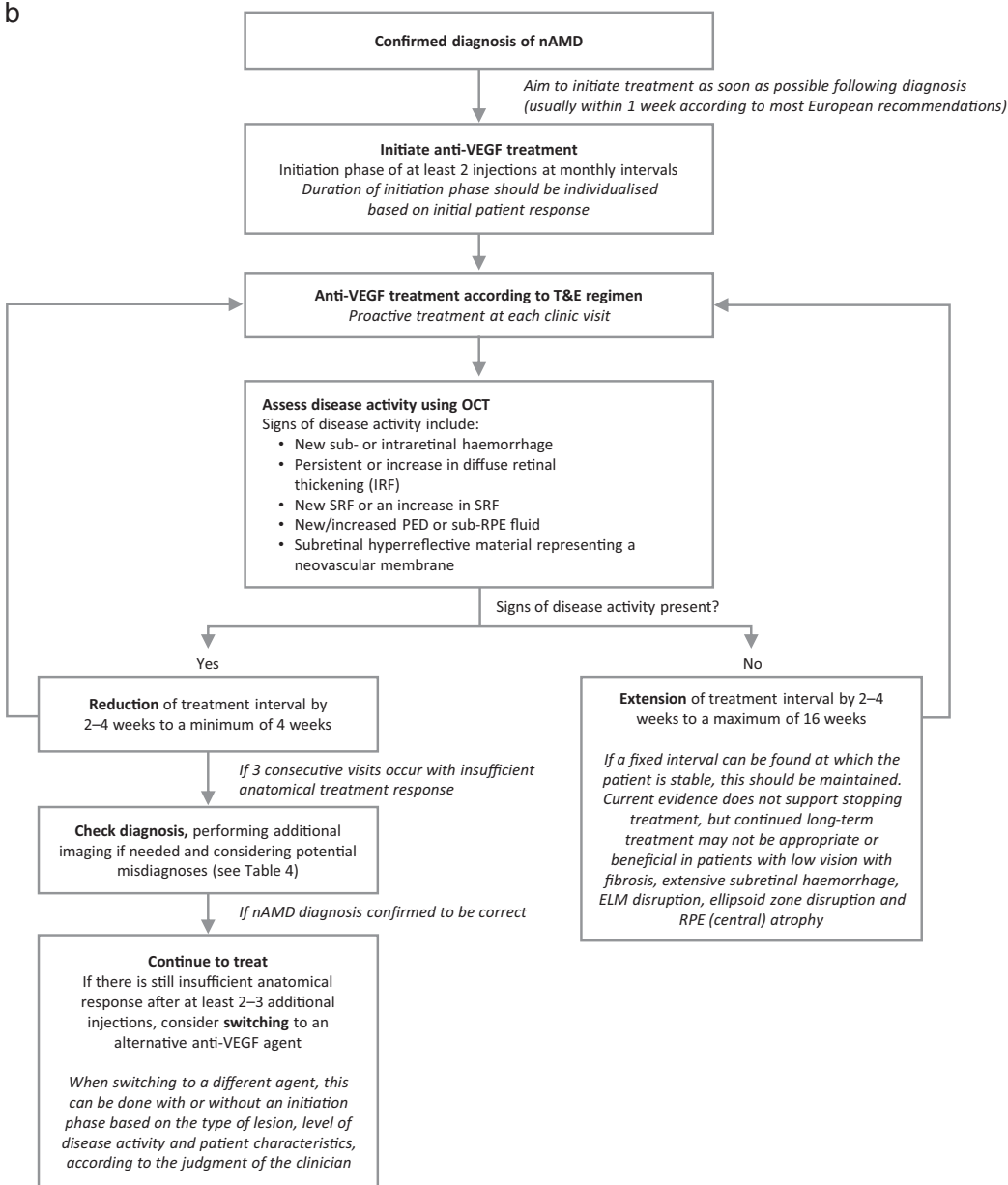

Fig. 2 Algorithm for the management of nAMD: recommendations by the consensus panel. a Diagnosis. $b$ Management according to a treatand-extend regimen. anti-VEGF anti-vascular endothelial growth factor, ELM external limiting membrane, ICGA indocyanine green angiography, IRF intraretinal fluid, FA fluorescein angiography, MNV macular neovascularisation, nAMD neovascular age-related macular degeneration, OCT optical coherence tomography, OCT-A optical coherence tomography angiography, PCV polypoidal choroidal vasculopathy, PED pigment epithelial detachment, RPE retinal pigment epithelium, SRF subretinal fluid, T\&E treat and extend. 


\section{Diagnosis and diagnostic techniques}

The consensus panel agreed that morphological parameters observed on OCT are the most important criteria in routine clinical practice for the diagnosis of nAMD. The whole stack of images should be used, to give as full a picture as possible. The characteristic features considered to be indicative of nAMD are SRF, IRF and fibrovascular PED (Fig. 2a). OCT can permit differentiation of the type of MNV and location of fluid, but at baseline many cases also require additional information from other imaging modalities in order to confirm the diagnosis. If available, OCTangiography (OCT-A) is considered to be valuable in order to visualise the neovascular complex. If OCT-A is not available, FA can be used to visualise leakage from the lesion, but is otherwise no longer judged to be a mandatory technique for nAMD diagnosis in all AMD cases. However, clinical signs visualised using biomicroscopy or fundus photography/examination are still considered useful to support the diagnosis. In cases where PCV or type $3 \mathrm{MNV}$ is suspected, ICGA and OCT-A are recommended to confirm this diagnosis. In addition to the morphological and clinical signs of nAMD, patient age over 50 years is an important criterion for a diagnosis of nAMD.

A range of conditions have the potential to masquerade as nAMD. Table 4 lists a number of these potential misdiagnoses or pitfalls. Of these, the most common are adultonset foveomacular vitelliform dystrophy and central serous chorioretinopathy. When examining a patient with putative nAMD, the clinician should be aware of and exclude these common differential diagnoses.

\section{Treatment}

The agreement of the consensus panel was that, regardless of the anti-VEGF agent used, T\&E is the recommended regimen for the management of nAMD because it provides comparable clinical outcomes to fixed monthly or bimonthly injections with a reduction in injection burden compared with fixed dosing [61, 62]. T\&E also provides a reduction in the number of clinic visits compared with PRN with monthly monitoring, provided that a one-step visit (with follow-up and injection on the same day) is possible. The potential for development of atrophy with intensive anti-VEGF therapy was considered to be less of a concern than the likelihood of visual acuity loss resulting from undertreatment, since a link between the number of injections and the risk of developing atrophy has never been proven. On the contrary, current evidence suggests that antiVEGF therapy is not a significant risk factor for the development of macular atrophy. For example, a post-hoc analysis of data from the HARBOR study reported no association of number of ranibizumab injections with
Table 4 Potential misdiagnoses for nAMD.

\begin{tabular}{|c|c|}
\hline Category & Condition \\
\hline \multirow[t]{5}{*}{ Inherited retinal diseases } & $\begin{array}{l}\text { Pattern dystrophy with pigment epithelial } \\
\text { detachment }\end{array}$ \\
\hline & $\begin{array}{l}\text { Adult-onset foveomacular vitelliform } \\
\text { dystrophy }\end{array}$ \\
\hline & Macular telangiectasia type 1 \\
\hline & $\begin{array}{l}\text { MNV secondary to Sorsby fundus } \\
\text { dystrophy }\end{array}$ \\
\hline & MNV secondary to Stargardt disease \\
\hline \multirow[t]{3}{*}{ Trauma and infection } & $\begin{array}{l}\text { MNV secondary to presumed ocular } \\
\text { histoplasmosis syndrome }\end{array}$ \\
\hline & MNV secondary to choroidal rupture \\
\hline & MNV secondary to trauma/laser pointers \\
\hline \multirow[t]{3}{*}{ Chorioretinal uveitis syndromes } & Inflammatory MNV \\
\hline & Chorioretinitis \\
\hline & $\begin{array}{l}\text { MNV secondary to punctate inner } \\
\text { choroidopathy }\end{array}$ \\
\hline \multirow[t]{6}{*}{ Retinopathies } & Diabetic maculopathy \\
\hline & Central serous chorioretinopathy \\
\hline & Pachychoroid neovasculopathy \\
\hline & Myopic MNV \\
\hline & Retinal vein occlusion \\
\hline & $\begin{array}{l}\text { Non-neovascular AMD, e.g., avascular } \\
\text { PEDs with or without pockets of SRF }\end{array}$ \\
\hline Neurodegenerative conditions & Macular telangiectasia type 2 \\
\hline \multirow[t]{6}{*}{ Other } & $\begin{array}{l}\text { Perifoveal exudative vascular anomalous } \\
\text { complex }\end{array}$ \\
\hline & Macroaneurysm \\
\hline & Epiretinal membrane \\
\hline & Vitreomacular traction \\
\hline & $\begin{array}{l}\text { MNV secondary to previous laser } \\
\text { photocoagulation in cases with } \\
\text { concomitant DMO }\end{array}$ \\
\hline & MNV secondary to angioid streaks \\
\hline $\begin{array}{l}\text { Degenerative structural features } \\
\text { that mimic neovascular activity }\end{array}$ & Outer retinal tubulation \\
\hline \multirow[t]{5}{*}{ (non-specific for AMD) } & Plateau sign \\
\hline & Apoptotic cysts \\
\hline & Pseudocysts \\
\hline & Hyporeflective wedge \\
\hline & Draping of drusen \\
\hline
\end{tabular}

$A M D$ age-related macular degeneration, $D M E$ diabetic macular oedema, $M N V$ macular neovascularization, $n A M D$ neovascular agerelated macular degeneration, $P E D$ pigment epithelial detachment, $S R F$ subretinal fluid.

macular atrophy development, and no significant association between regimen (monthly vs PRN treatment) and macular atrophy development [63]. Another post-hoc analysis of data from the same trial using Classification of Atrophy Meetings (CAM) group atrophy criteria found no differences in the incidence or progression rates of new macular atrophy among study arms, anti-VEGF doses, or treatment regimens [64]. However, there is evidence that neovascularisation type may be associated with the development of atrophy, with patients with type $1 \mathrm{MNV}$ at baseline less likely to develop atrophy than eyes with other forms of MNV [65]. In contrast, patients with type $3 \mathrm{MNV}$ 
and subretinal drusenoid deposits at baseline have a high risk of atrophy development [66].

Treatment with anti-VEGF therapy should be initiated as soon as possible once the diagnosis of nAMD is made. Guidelines and institutional guidance vary throughout Europe, with most recommendations advising that treatment should take place within 1 week of referral. The NICE guidelines mandate treatment within 14 days of referral, but specify that referral should take place within 1 working day of diagnosis [7]. Treatment should begin with an initiation phase before the clinician considers extending the treatment interval (Fig. 2b). This usually consists of three injections given at monthly intervals, but in some circumstances (as seen in real-world datasets [67]) could entail just two injections depending on the response of the individual patient. After that, the patient is evaluated for extension criteria, and the treatment interval can be increased by 2-4 weeks at a time.

Treatment should be given proactively at each visit-a key aspect of T\&E treatment design. The decision on whether the treatment interval should be extended, retained, or reduced is also made at each visit, and is based on disease activity as assessed using OCT. The signs of disease activity that should trigger a reduction in treatment interval include new haemorrhage beneath or within the retina, new or persistent IRF, new or increased SRF, increased size of PED, or the presence of subretinal hyperreflective material which would indicate the presence of a neovascular membrane. If one or more of these signs are present, the treatment interval should be reduced by 2-4 weeks, to a minimum of 4 weeks. However, in a minority of cases with recurrent disease activity, the clinician may feel that an extension or reduction of 1 week might be more appropriate.

If disease activity is observed at three consecutive visits, with no sign of anatomical and/or functional improvement, the clinician should consider whether the initial diagnosis of nAMD was correct, using additional imaging modalities to provide more information if necessary. It might be possible that the patient is not a non-responder but has instead been misdiagnosed for nAMD. If further investigation confirms the original diagnosis, then the consensus panel recommends that treatment should be continued for at least 2 to 3 additional injections at the minimum interval permitted by the product label before a switch to an alternative antiVEGF therapy is considered. If a patient is switched to a different anti-VEGF therapy due to lack of efficacy, this should be done with a new initiation phase. However, a simulated switching study has suggested that continuation of initial therapy will, in many cases, result in a gradual improvement or stabilisation similar to that commonly reported following a therapy switch in published anti-VEGF switching studies [68].
If there is no evidence of disease activity at the treatment visit, the clinician may consider extending the treatment interval by 2-4 weeks [69], to a maximum of 16 weeks (or potentially more with longer-acting anti-VEGF agents), however, there will be a higher risk of recurrence [67]. If a patient reaches stability at a particular treatment interval, this should be maintained over the long term if feasible. If the treatment interval is alternately being extended and reduced at each visit, the clinician can consider that the shorter of the two intervals is the more appropriate one for the patient and maintain this interval for a period of time before re-evaluating the patient's treatment needs in due course. There is currently no evidence to support stopping anti-VEGF treatment in patients with stable disease, as disease activity will very likely recur, but the clinician may consider that continued long-term anti-VEGF therapy may not be appropriate or beneficial in patients with low vision who have fibrosis, extensive subretinal haemorrhage, subfoveal disruption of the external limiting membrane or the ellipsoid zone or central atrophy of the RPE.

\section{Discussion and conclusion}

The aim of this consensus article is to consider the evidence and guidance currently available in the scientific literature on the role of fluid in the management of nAMD and provide recommendations as to how it might be integrated into everyday clinical practice based on the opinion of a panel of expert retinal specialists. Our understanding of the role of fluid in nAMD is still evolving and in some instances the observations reported in the scientific literature are conflicting and confusing. The treatment recommendations provided here are based on our best interpretation of the available data at this time. The resulting algorithm for the diagnosis and management of nAMD provides clear guidance on recommended diagnostic tools and what they can be used to identify, as well as a simple treatment pathway based on the $T \& E$ regimen. It aims to provide the best possible visual outcomes for patients whilst acknowledging the restrictions that are inevitably encountered in real-world clinical practice. Treatment decisions are made according to observations of fluid as a biomarker for disease activity in nAMD. This publication is not an exhaustive review of the $\mathrm{T} \& \mathrm{E}$ regimen, which varies in detail between publications, but provides a recommended version of the $T \& E$ regimen based on the combined clinical experience of the consensus panel, and guided by fluid.

The detection of fluid on OCT is generally used to imply the presence of a VEGF-related leak that the clinician could expect to respond to anti-VEGF therapy. However, in some cases, the fluid spaces seen on OCT may actually be structural changes such as outer retinal tubulation that are 
not responsive to anti-VEGF treatment [70]. Where this is suspected, strategies to confirm that fluid is VEGF-driven include monitoring patients shortly after treatment (e.g., 2 weeks after injection) to check for a short-lived treatment response, checking for leakage from the lesion using FA, and assessing whether the putative fluid worsens with an extended treatment interval.

There are a number of limitations associated with this review and consensus. The scientific evidence reviewed here is limited in that the literature search retrieved only one level 1 evidence trial (the FLUID study) that specifically aimed to evaluate the impact of fluid in the management of nAMD [19]. Even this study had limitations in terms of determining the effect of treating fluid versus leaving it untreated since patients were treated at every visit in both treatment arms. Interestingly, both the arms where SRF was more tolerated and the arm where it was treated more aggressively had relatively high and nearly identical injection frequencies (means of 15.8 and 17 injections over 2 years). The remainder of the evidence comes from a number of RCTs in which the effect of fluid on treatment outcomes was an observational, secondary or exploratory outcome or the subject of a post-hoc analysis, or in the form of lower level evidence from prospective but uncontrolled trials and retrospective chart reviews. For the purposes of this review, all publications that met the literature review inclusion criteria have been considered, regardless of the level of evidence.

The imaging technologies used in the studies included here have not remained constant over the time span of the literature review. OCT has evolved from time domain to spectral domain modalities, meaning that the observations reported by the earliest publications returned by the literature search are not directly comparable to the more recent publications. Several of the larger RCTs used these older imaging techniques, which may detract from the relevance of their findings to current practice. Other measured parameters may have also changed over time.

A final limitation of this work is that for the purposes of providing clear guidance that can be used on a day-to-day basis by the practising clinician, this review and consensus focusses only on the role of fluid in nAMD. In addition to fluid, a range of other morphological features visible on OCT such as external limiting membrane, ellipsoid zone and RPE disruption, and the presence of PED and hyperreflective material have been associated with poor visual acuity outcomes [23, 24, 27-29, 31, 35, 40, 42, 45, 49-52, 71-75]. A relationship has also been observed between visual acuity outcomes and the type of neovascularisation. At baseline, type $1 \mathrm{MNV}$ is a predictor of better visual acuity following antiVEGF treatment compared with other lesion types, and eyes with this type of lesion often have SRF [76]. These associated morphological findings are also important features with prognostic value which can co-exist with fluid. However, given the difficulties in visualising, identifying and consistently assessing some of these other features, we are of the opinion that fluid is the most practical and useful biomarker of VEGF upregulation and MNV activity in nAMD.

In conclusion, gaps exist in the scientific literature on the role of fluid in the management of patients with nAMD. The limitations described here highlight the real need for appropriately designed and executed studies to provide a standardised and detailed understanding of the appearance of different specific fluid manifestations and their consequences on clinical outcomes. However, it is quite clear that the primary treatment goal is to eliminate fluid as effectively as possible. Future research into this important area could provide valuable insights to direct optimal treatment to achieve this. In the meantime, following expert consideration of the evidence available, we recommend that patients with nAMD receive anti-VEGF therapy according to a T\&E regimen with treatment intervals determined according to fluid-based disease activity parameters observed using OCT.

Acknowledgements Jennifer Green, PhD (Green Ink Communications Limited; funded by Novartis Pharma AG) provided assistance with medical writing and reviewing the studies identified by the search for inclusion/exclusion, under the direction of the authors.

Author contributions The expert consensus panel (LK, MP, RDM, FGH, MRM, MN, FR, RS, SJT, JZV and SAZ) interpreted the scientific evidence and developed the treatment recommendations. SAZ, $\mathrm{AC}$ and RKV developed the initial concept for the publication. All authors reviewed/revised the manuscript and approved the final version. All authors agree to be accountable for all aspects of the work in ensuring that questions related to the accuracy or integrity of any part of the work are appropriately investigated and resolved. The corresponding author had full access to the data included in this publication and had final responsibility for the decision to submit for publication.

Funding Financial support for medical writing assistance was provided by Novartis Pharma AG (Basel, Switzerland). The authors did not receive financial compensation for this work. Open Access funding provided by Universität Zürich.

\section{Compliance with ethical standards}

Conflict of interest LK is a consultant for Allergan, Alimera, Bayer, Horus, Krys, Novartis, Roche and Théa. MP is a consultant for Allergan, Novartis, Bayer, and Zeiss outside the submitted work. AC and RKV are full time employees and shareholders at Novartis Pharma A.G. RDM is a consultant for Heidelberg Engineering, Novartis and Allergan, and receives research support from Genentech/Roche. FGH is a consultant for and/or has received funding for research from: Acucela, Allergan, Apellis, Bayer, Boehringer-Ingelheim, Bioeq/Formycon, CenterVue, Ellex, Roche/Genentech, Geuder, Grayburg Vision, Heidelberg Engineering, Kanghong, LinBioscience, NightStarX, Novartis, Optos, Pixium Vision, Oxurion, Stealth BioTherapeutic, and Zeiss. MRM is a consultant for Zeiss, Lumithera, Bayer, Novartis and Oculis. MN is a consultant for and/or has received 
funding for research from: Allergan, Bayer, Novartis and Sifi. FR is a consultant for Allergan, Alimera, Bayer, MS\&D, Novartis and Roche. RS is a consultant for Allergan, Alimera, Bayer, Novartis and Théa. SJT is a consultant for Bayer and Novartis, received grant support from Bayer, Novartis and Heidelberg Engineering, and is involved in research for Allergan, Roche, Bayer, Novartis and BoehringerIngelheim. JZV is a consultant for Alcon, Alimera Sciences, Allergan, Bayer, Novartis and Roche, has received grants from Allergan and Novartis and is a lecturer for Bausch and Lomb, DORC, Topcon and Zeiss. SAZ is a consultant for Allergan, Bayer HealthCare, Novartis and Roche and has received grant support from Bayer HealthCare and Novartis.

Publisher's note Springer Nature remains neutral with regard to jurisdictional claims in published maps and institutional affiliations.

Open Access This article is licensed under a Creative Commons Attribution 4.0 International License, which permits use, sharing, adaptation, distribution and reproduction in any medium or format, as long as you give appropriate credit to the original author(s) and the source, provide a link to the Creative Commons license, and indicate if changes were made. The images or other third party material in this article are included in the article's Creative Commons license, unless indicated otherwise in a credit line to the material. If material is not included in the article's Creative Commons license and your intended use is not permitted by statutory regulation or exceeds the permitted use, you will need to obtain permission directly from the copyright holder. To view a copy of this license, visit http://creativecommons. org/licenses/by/4.0/.

\section{References}

1. Staurenghi G, Sadda S, Chakravarthy U, Spaide RF. International Nomenclature for Optical Coherence Tomography Panel. Proposed lexicon for anatomic landmarks in normal posterior segment spectral-domain optical coherence tomography: the IN*OCT consensus. Ophthalmology. 2014;121:1572-8.

2. Li Y, Xia X, Paulus YM. Advances in retinal optical imaging. Photonics. 2018;5:9.

3. Chakravarthy U, Soubrane G, Bandello F, Chong V, CreuzotGarcher C, Dimitrakos SA 2nd, et al. Evolving European guidance on the medical management of neovascular age related macular degeneration. Br J Ophthalmol. 2006;90:1188-96.

4. Spaide RF, Jaffe GJ, Sarraf D, Freund KB, Sadda SR, Staurenghi $\mathrm{G}$, et al. Consensus nomenclature for reporting neovascular agerelated macular degeneration data: consensus on neovascular agerelated macular degeneration nomenclature study group. Ophthalmology. 2020;127:616-36.

5. Amoaku W. Ranibizumab: the clinician's guide to commencing, continuing, and discontinuing treatment. Eye. 2009;23:2140-2.

6. Chakravarthy U, Williams M. AMD Guidelines Group. The Royal College of Ophthalmologists guidelines on AMD: executive summary. Eye. 2013;27:1429-31.

7. National Institute for Health and Care Excellence. Age-related macular degeneration. NICE guidelines [NG82]. 2018. https://www.nice.org.uk/guidance/ng82. Accessed September 2019.

8. Schmidt-Erfurth U, Chong V, Loewenstein A, Larsen M, Souied E, Schlingemann R, et al. Guidelines for the management of neovascular age-related macular degeneration by the European Society of Retina Specialists (EURETINA). Br J Ophthalmol. 2014;98:1144-67.
9. American Academy of Ophthalmology. Age-related macular degeneration preferred practice pattern. 2015. https://www.aao. org/preferred-practice-pattern/age-related-macular-degenerationppp-2015. Accessed September 2019.

10. Rodrigues IA, Sprinkhuizen SM, Barthelmes D, Blumenkranz M, Cheung G, Haller J, et al. Defining a minimum set of standardized patient-centered outcome measures for macular degeneration. Am J Ophthalmol. 2016;168:1-12.

11. Pauleikhoff D, Kirchhof B. Retreatment criteria in anti-VEGF therapy of exudative AMD: critical analysis of present regimes and new morphological definition of "lesion activity". Graefes Arch Clin Exp Ophthalmol. 2011;249:631-2.

12. Amoaku WM, Chakravarthy U, Gale R, Gavin M, Ghanchi F, Gibson $\mathrm{J}$, et al. Defining response to anti-VEGF therapies in neovascular AMD. Eye. 2015;29:721-31.

13. Patel PJ, Devonport H, Sivaprasad S, Ross AH, Walters G, Gale $\mathrm{RP}$, et al. Aflibercept treatment for neovascular AMD beyond the first year: consensus recommendations by a UK expert roundtable panel, 2017 update. Clin Ophthalmol. 2017;11:1957-66.

14. Androudi S, Dastiridou A, Pharmakakis N, Stefaniotou M, Kalogeropoulos C, Symeonidis C, et al. Guidelines for the management of wet age-related macular degeneration: recommendations from a panel of Greek experts. Adv Ther. 2016;33:715-26.

15. Mowatt G, Hernandez R, Castillo M, Lois N, Elders A, Fraser C, et al. Optical coherence tomography for the diagnosis, monitoring and guiding of treatment for neovascular age-related macular degeneration: a systematic review and economic evaluation. Health Technol Assess. 2014;18:1-254.

16. Schmidt-Erfurth U, Waldstein SM. A paradigm shift in imaging biomarkers in neovascular age-related macular degeneration. Prog Retin Eye Res. 2016;50:1-24.

17. Schmidt-Erfurth U, Klimscha S, Waldstein SM, Bogunovic H. A view of the current and future role of optical coherence tomography in the management of age-related macular degeneration. Eye. 2017;31:26-44.

18. Ashraf M, Souka A, Adelman RA. Age-related macular degeneration: using morphological predictors to modify current treatment protocols. Acta Ophthalmol. 2018;96:120-33.

19. Guymer RH, Markey CM, McAllister IL, Gillies MC, Hunyor AP, Arnold JJ, et al. Tolerating subretinal fluid in neovascular agerelated macular degeneration treated with ranibizumab using a treat-and-extend regimen: FLUID study 24-month results. Ophthalmology. 2019;126:723-34.

20. Keane PA, Patel PJ, Ouyang Y, Chen FK, Ikeji F, Walsh AC, et al. Effects of retinal morphology on contrast sensitivity and reading ability in neovascular age-related macular degeneration. Investig Ophthalmol Vis Sci. 2010;51:5431-7.

21. Brown DM, Tuomi L, Shapiro H. Pier Study G. Anatomical measures as predictors of visual outcomes in ranibizumab-treated eyes with neovascular age-related macular degeneration. Retina. 2013;33:23-34.

22. Jaffe GJ, Martin DF, Toth CA, Daniel E, Maguire MG, Ying GS, et al. Macular morphology and visual acuity in the comparison of age-related macular degeneration treatments trials. Ophthalmology. 2013;120:1860-70.

23. Ying GS, Kim BJ, Maguire MG, Huang J, Daniel E, Jaffe GJ, et al. Sustained visual acuity loss in the comparison of age-related macular degeneration treatments trials. JAMA Ophthalmol. 2014;132:915-21.

24. Shah N, Maguire MG, Martin DF, Shaffer J, Ying GS, Grunwald $\mathrm{JE}$, et al. Angiographic cystoid macular edema and outcomes in the comparison of age-related macular degeneration treatments trials. Ophthalmology. 2016;123:858-64.

25. Sharma S, Toth CA, Daniel E, Grunwald JE, Maguire MG, Ying GS, et al. Macular morphology and visual acuity in the second 
year of the comparison of age-related macular degeneration treatments trials. Ophthalmology. 2016;123:865-75.

26. Ying GS, Maguire MG, Pan W, Grunwald JE, Daniel E, Jaffe GJ, et al. Baseline predictors for five-year visual acuity outcomes in the comparison of AMD treatment trials. Opthalmol Retina. 2018;2:525-30.

27. Jaffe GJ, Ying GS, Toth CA, Daniel E, Grunwald JE, Martin DF, et al. Macular morphology and visual acuity in year five of the comparison of age-related macular degeneration treatments trials. Ophthalmology. 2019;126:252-60.

28. Ritter M, Simader C, Bolz M, Deak GG, Mayr-Sponer U, Sayegh $\mathrm{R}$, et al. Intraretinal cysts are the most relevant prognostic biomarker in neovascular age-related macular degeneration independent of the therapeutic strategy. $\mathrm{Br} \mathrm{J}$ Ophthalmol. 2014;98:1629-35.

29. Simader C, Ritter M, Bolz M, Deak GG, Mayr-Sponer U, Golbaz I, et al. Morphologic parameters relevant for visual outcome during anti-angiogenic therapy of neovascular age-related macular degeneration. Ophthalmology. 2014;121:1237-45.

30. Waldstein SM, Wright J, Warburton J, Margaron P, Simader C, Schmidt-Erfurth U. Predictive value of retinal morphology for visual acuity outcomes of different ranibizumab treatment regimens for neovascular AMD. Ophthalmology. 2016; 123:60-69.

31. Kodjikian L, Decullier E, Souied EH, Roux A, Aulagner G, Huot $\mathrm{L}$, et al. Predictors of one-year visual outcomes after anti-vascular endothelial growth factor treatment for neovascular age-related macular degeneration. Retina. 2018;38:1492-9.

32. Schmidt-Erfurth U, Waldstein SM, Deak GG, Kundi M, Simader C. Pigment epithelial detachment followed by retinal cystoid degeneration leads to vision loss in treatment of neovascular agerelated macular degeneration. Ophthalmology. 2015;122:822-32.

33. Jaffe GJ, Kaiser PK, Thompson D, Gibson A, Saroj N, Vitti R, et al. Differential response to anti-VEGF regimens in age-related macular degeneration patients with early persistent retinal fluid. Ophthalmology. 2016;123:1856-64.

34. Moshfeghi DM, Hariprasad SM, Marx JL, Thompson D, Soo Y, Gibson A, et al. Effect of fluid status at week 12 on visual and anatomic outcomes at week 52 in the VIEW 1 and 2 trials. Ophthalmic Surg Lasers Imaging. Retina. 2016;47:238-44.

35. Waldstein SM, Simader C, Staurenghi G, Chong NV, Mitchell P, Jaffe GJ, et al. Morphology and visual acuity in aflibercept and ranibizumab therapy for neovascular age-related macular degeneration in the VIEW trials. Ophthalmology. 2016;123:1521-9.

36. Khurana RN, Rahimy E, Joseph WA, Saroj N, Gibson A, Vitti R, et al. Extended (every 12 weeks or longer) dosing interval with intravitreal aflibercept and ranibizumab in neovascular age-related macular degeneration: post hoc analysis of VIEW trials. Am J Ophthalmol. 2019;200:161-8.

37. Regillo CD, Busbee BG, Ho AC, Ding B, Haskova Z. Baseline predictors of 12-month treatment response to ranibizumab in patients with wet age-related macular degeneration. Am J Ophthalmol. 2015;160:1014-23. e1012.

38. Schmidt-Erfurth U, Bogunovic H, Sadeghipour A, Schlegl T, Langs G, Gerendas BS, et al. Machine learning to analyze the prognostic value of current imaging biomarkers in neovascular age-related macular degeneration. Ophthalmol Retina. 2018;2: 24-30.

39. Hu X, Waldstein SM, Klimscha S, Sadeghipour A, Bogunovic H, Gerendas BS, et al. Morphological and functional characteristics at the onset of exudative conversion in age-related macular degeneration. Retina. 2020;40:1070-8.

40. Casalino G, Bandello F, Chakravarthy U. Changes in neovascular lesion hyperreflectivity after anti-VEGF treatment in age-related macular degeneration: an integrated multimodal imaging analysis. Investig Ophthalmol Vis Sci. 2016;57:OCT288-298.
41. Segal O, Barayev E, Nemet AY, Mimouni M. Predicting response of exudative age-related macular degeneration to bevacizumab based on spectralis optical coherence tomography. Retina. 2016;36:259-63.

42. Vogel RN, Davis DB, Kimura BH, Rathinavelu S, Graves GS, Szabo A, et al. Neovascular age-related macular degeneration with advanced visual loss treated with anti-vascular endothelial growth factor therapy: Clinical outcome and prognostic indicators. Retina. 2017;37:257-64.

43. Arnold JJ, Markey CM, Kurstjens NP, Guymer RH. The role of sub-retinal fluid in determining treatment outcomes in patients with neovascular age-related macular degeneration-a phase IV randomised clinical trial with ranibizumab: the FLUID study. BMC Ophthalmol. 2016;16:31.

44. Wickremasinghe SS, Janakan V, Sandhu SS, Amirul-Islam FM, Abedi F, Guymer RH. Implication of recurrent or retained fluid on optical coherence tomography for visual acuity during active treatment of neovascular age-related macular degeneration with a treat and extend protocol. Retina. 2016;36:1331-9.

45. Dervenis N, Younis S. Macular morphology and response to ranibizumab treatment in patients with wet age-related macular degeneration. Clin Ophthalmol. 2016;10:1117-22.

46. Lee H, Jo A, Kim HC. Three-dimensional analysis of morphologic changes and visual outcomes in neovascular age-related macular degeneration. Invest Ophthalmol Vis Sci. 2017;58:1337-45.

47. Shin JY, Woo SJ, Ahn J, Park KH. Anti-VEGF-refractory exudative age-related macular degeneration: differential response according to features on optical coherence tomography. Korean $\mathbf{J}$ Ophthalmol. 2013;27:425-32.

48. Sagiv O, Zloto O, Moroz I, Moisseiev J. Different clinical courses on long-term follow-up of age-related macular degeneration patients treated with intravitreal anti-vascular endothelial growth factor injections. Ophthalmologica. 2017;238:217-25.

49. Chatziralli I, Nicholson L, Vrizidou E, Koutsiouki C, Menon D, Sergentanis TN, et al. Predictors of outcome in patients with neovascular age-related macular degeneration switched from ranibizumab to 8-weekly aflibercept. Ophthalmology. 2016;123: $1762-70$.

50. Wickremasinghe SS, Sandhu SS, Busija L, Lim J, Chauhan DS, Guymer RH. Predictors of AMD treatment response. Ophthalmology. 2012;119:2413.e5.

51. Pokroy R, Mimouni M, Barayev E, Segev F, Geffen N, Nemet AY, et al. Prognostic value of subretinal hyperreflective material in neovascular age-related macular degeneration treated with bevacizumab. Retina. 2018;38:1485-91.

52. Segal O, Barayev E, Nemet AY, Geffen N, Vainer I, Mimouni M. Prognostic value of hyperreflective foci in neovascular age-related macular degeneration treated with bevacizumab. Retina. 2016; 36:2175-82.

53. Padnick-Silver L, Weinberg AB, Lafranco FP, Macsai MS. Pilot study for the detection of early exudative age-related macular degeneration with optical coherence tomography. Retina. 2012;32:1045-56.

54. Fulcher C, Hazel CA, Pacey I, Ali H, Ghanchi FD. Predicting visual outcomes in patients treated with aflibercept for neovascular age-related macular degeneration: data from a real-world clinical setting. Eur J Ophthalmol. 2020;30:543-9.

55. Kolb S, Menghini M, Barthelmes D, Sutter F, Kurz-Levin M. The predictive value of OCT characteristics for the visual outcome in neovascular AMD. Klin Monbl Augenheilkd. 2012;229:343-7.

56. Shin JY, Kwon KY, Byeon SH. Association between choroidal thickness and the response to intravitreal ranibizumab injection in age-related macular degeneration. Acta Ophthalmol. 2015;93: 524-32.

57. Keane PA, Liakopoulos S, Chang KT, Wang M, Dustin L, Walsh $\mathrm{AC}$, et al. Relationship between optical coherence tomography 
retinal parameters and visual acuity in neovascular age-related macular degeneration. Ophthalmology. 2008;115:2206-14.

58. Roh M, Lains I, Shin HJ, Park DH, Mach S, Vavvas DG, et al. Microperimetry in age-related macular degeneration: association with macular morphology assessed by optical coherence tomography. Br J Ophthalmol. 2019;103:1769-76.

59. Koizumi H, Kano M, Yamamoto A, Saito M, Maruko I, Sekiryu $\mathrm{T}$, et al. Subfoveal choroidal thickness during aflibercept therapy for neovascular age-related macular degeneration: twelve-month results. Ophthalmology. 2016;123:617-24.

60. Kumar JB, Wai KM, Ehlers JP, Singh RP, Rachitskaya AV. Subfoveal choroidal thickness as a prognostic factor in exudative age-related macular degeneration. Br J Ophthalmol. 2019;103: 918-21.

61. Silva R, Berta A, Larsen M, Macfadden W, Feller C, Mones J, et al. Treat-and-extend versus monthly regimen in neovascular age-related macular degeneration: results with ranibizumab from the TREND study. Ophthalmology. 2018;125:57-65.

62. Haga A, Kawaji T, Ideta R, Inomata Y, Tanihara H. Treat-andextend versus every-other-month regimens with aflibercept in agerelated macular degeneration. Acta Ophthalmol. 2018;96: e393-e398.

63. Sadda SR, Tuomi LL, Ding B, Fung AE, Hopkins JJ. Macular atrophy in the HARBOR study for neovascular age-related macular degeneration. Ophthalmology. 2018;125:878-86.

64. Gune S, Abdelfattah NS, Karamat A, Balasubramanian S, Marion KM, Morgenthien E, et al. Spectral-domain OCT-based prevalence and progression of macular atrophy in the HARBOR study for neovascular age-related macular degeneration. Ophthalmology. 2020;127:523-32.

65. Xu L, Mrejen S, Jung JJ, Gallego-Pinazo R, Thompson D, Marsiglia $\mathrm{M}$, et al. Geographic atrophy in patients receiving antivascular endothelial growth factor for neovascular age-related macular degeneration. Retina. 2015;35:176-86.

66. Baek J, Lee JH, Kim JY, Kim NH, Lee WK. Geographic atrophy and activity of neovascularization in retinal angiomatous proliferation. Investig Ophthalmol Vis Sci. 2016;57:1500-5.

67. Gillies MC, Campain A, Barthelmes D, Simpson JM, Arnold JJ, Guymer RH, et al. Long-term outcomes of treatment of neovascular age-related macular degeneration: data from an observational study. Ophthalmology. 2015;122:1837-45.

68. Zarbin M, Tsuboi M, Hill LF, Stoilov I. Simulating an antivascular endothelial growth factor switch in neovascular agerelated macular degeneration: a HARBOR subanalysis. Ophthalmology. 2019;126:849-55.

69. Ohji M, Takahashi K, Okada AA, Kobayashi M, Matsuda Y, Terano Y, et al. Efficacy and safety of intravitreal aflibercept treatand-extend regimens in exudative age-related macular degeneration: 52- and 96-week findings from ALTAIR: a randomized controlled trial. Adv Ther. 2020;37:1173-87.

70. Zweifel SA, Engelbert M, Laud K, Margolis R, Spaide RF, Freund KB. Outer retinal tubulation: a novel optical coherence tomography finding. Arch Ophthalmol. 2009;127:1596-602.

71. Kashani AH, Keane PA, Dustin L, Walsh AC, Sadda SR. Quantitative subanalysis of cystoid spaces and outer nuclear layer using optical coherence tomography in age-related macular degeneration. Investig Ophthalmol Vis Sci. 2009;50:3366-73.
72. Kim JH, Chang YS, Kim JW, Kim CG, Lee DW. Abrupt visual loss during anti-vascular endothelial growth factor treatment for type 3 neovascularization. Int J Ophthalmol. 2019;12:480-7.

73. Mariani A, Deli A, Ambresin A, Mantel I. Characteristics of eyes with secondary loss of visual acuity receiving variable dosing ranibizumab for neovascular age-related macular degeneration. Graefes Arch Clin Exp Ophthalmol. 2011;249:1635-42.

74. Lai TT, Hsieh YT, Yang CM, Ho TC, Yang CH. Biomarkers of optical coherence tomography in evaluating the treatment outcomes of neovascular age-related macular degeneration: a realworld study. Sci Rep. 2019;9:529.

75. Lee H, Ji B, Chung H, Kim HC. Correlation between optical coherence tomographic hyperreflective foci and visual outcomes after anti-VEGF treatment in neovascular age-related macular degeneration and polypoidal choroidal vasculopathy. Retina. 2016;36:465-75.

76. Mrejen S, Jung JJ, Chen C, Patel SN, Gallego-Pinazo R, Yannuzzi $\mathrm{N}$, et al. Long-term visual outcomes for a treat and extend antivascular endothelial growth factor regimen in eyes with neovascular age-related macular degeneration. J Clin Med. 2015;4: 1380-402.

77. Dadgostar H, Ventura AA, Chung JY, Sharma S, Kaiser PK. Evaluation of injection frequency and visual acuity outcomes for ranibizumab monotherapy in exudative age-related macular degeneration. Ophthalmology. 2009;116:1740-7.

78. Unver YB, Yavuz GA, Bekiroglu N, Presti P, Li W, Sinclair SH. Relationships between clinical measures of visual function and anatomic changes associated with bevacizumab treatment for choroidal neovascularization in age-related macular degeneration. Eye. 2009;23:453-60.

79. Silva R, Cachulo ML, Fonseca $P$, Bernardes $R$, Nunes $S$, Vilhena $\mathrm{N}$, et al. Age-related macular degeneration and risk factors for the development of choroidal neovascularisation in the fellow eye: A 3-year follow-up study. Ophthalmologica. 2011; 226:110-8.

80. Gianniou C, Dirani A, Jang L, Mantel I. Refractory intraretinal or subretinal fluid in neovascular age-related macular degeneration treated with intravitreal ranizubimab: functional and structural outcome. Retina. 2015;35:1195-201.

81. Lin T, Dans KC, Muftuoglu IK, Meshi A, Amador-Patarroyo MJ, Cheng L, et al. Factors associated with extended remission in neovascular age-related macular degeneration on pro re nata treatment protocol. Br J Ophthalmol. 2020;104:58-63.

82. CATT Research Group, Martin DF, Maguire MG, Ying GS, Grunwald JE, Fine SL, et al. Ranibizumab and bevacizumab for neovascular age-related macular degeneration. N Engl J Med. 2011;364:1897-908.

83. Ho AC, Busbee BG, Regillo CD, Wieland MR, Van Everen SA, $\mathrm{Li} \mathrm{Z}$, et al. Twenty-four-month efficacy and safety of $0.5 \mathrm{mg}$ or $2.0 \mathrm{mg}$ ranibizumab in patients with subfoveal neovascular age-related macular degeneration. Ophthalmology. 2014;121: 2181-92.

84. Kodjikian L, Souied EH, Mimoun G, Mauget-Faysse M, BeharCohen F, Decullier E, et al. Ranibizumab versus bevacizumab for neovascular age-related macular degeneration: results from the GEFAL noninferiority randomized trial. Ophthalmology. 2013;120:2300-9. 